\title{
Macrophages-derived exosomal IncRNA LIFR-AS1 promotes osteosarcoma cell progression via miR-29a/NFIA axis
}

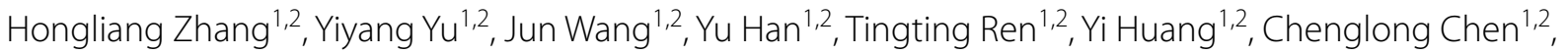
Qingshan Huang ${ }^{1,2}$, Wei Wang ${ }^{1,2}$, Jianfang Niu' ${ }^{1,2}$, Jingbing Lou ${ }^{1,2}$ and Wei Guo ${ }^{1,2^{*}}$ (D)

\begin{abstract}
Background: Osteosarcoma (OS) is the most common primary malignant bone tumor in young people. Tumorassociated macrophages (TAMs) have been reported to play an important role in the development of osteosarcoma. However, the detailed molecular mechanisms remain largely unknown and need to be elucidated. Recently, exosomes have been reported as the crucial mediator between tumor cells and the tumor microenvironment. And a lot of IncRNAs have been reported to act as either oncogenes or tumor suppressors in osteosarcoma. In this research, we aim to explore the role of macrophages-derived exosomal IncRNA in osteosarcoma development and further elucidated the potential molecular mechanisms involved.
\end{abstract}

Methods: TAMs were differentiated from human mononuclear cells THP-1, and a high-throughput microarray assay was used to analyze the dysregulated IncRNAs and miRNAs in osteosarcoma cells co-cultured with macrophagesderived exosomes. Western blot, qRT-PCR assays, and Dual-luciferase reporter assay were used to verify the interaction among LIFR-AS1, miR-29a, and NFIA. Cck-8, EdU, colony formation assay, wound-healing, and transwell assay were performed to explore the characterize the proliferation and metastasis ability of OS cells. And GPCR, Western blots, immunohistochemistry, and cell immunofluorescence were used to detect the expression of relative genes or proteins.

Results: In this study, we found that THP-1-induced macrophage-derived exosomes could facilitate osteosarcoma cell progression both in vitro and in vivo. Then, the results of the high-throughput microarray assay showed that LIFR-AS1 was highly expressed and miR-29a was lowly expressed. Furthermore, LIFR-AS1 was identified as a miR-29a sponge, and NFIA was validated as a direct target of miR-29a. Functional assays demonstrated that knockdown of exosomal LIFR-AS1 could attenuate the promotion effects of macrophages-derived exosomes on osteosarcoma cell progression and miR-29a inhibition could reserve the effect of LIFR-AS1-knockdown exosomes. Correspondingly, NFIA-knockdown could partially reverse the tumor inhibition effect of miR-29a on osteosarcoma cells.

Conclusions: Taken together, macrophages-derived exosomal IncRNA LIFR-AS1 can promote osteosarcoma cell proliferation, invasion, and restrain cell apoptosis via miR-29a/NFIA axis, which can act as a potential novel therapeutic target for osteosarcoma therapy.

Keywords: Bone tumor, Tumor-associated macrophages, Exosomal IncRNA, LIFR-AS1, Exosome

\footnotetext{
*Correspondence: 1811110346@bjmu.edu.cn

1 Musculoskeletal Tumor Center, Peking University People's Hospital, No.

11 Xizhimen South Street, Beijing 100044, People's Republic of China

Full list of author information is available at the end of the article
}

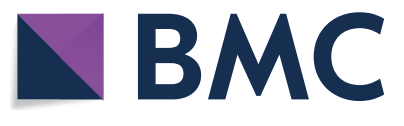

(c) The Author(s) 2021. This article is licensed under a Creative Commons Attribution 4.0 International License, which permits use, sharing, adaptation, distribution and reproduction in any medium or format, as long as you give appropriate credit to the original author(s) and the source, provide a link to the Creative Commons licence, and indicate if changes were made. The images or other third party material in this article are included in the article's Creative Commons licence, unless indicated otherwise in a credit line to the material. If material is not included in the article's Creative Commons licence and your intended use is not permitted by statutory regulation or exceeds the permitted use, you will need to obtain permission directly from the copyright holder. To view a copy of this licence, visit http://creativeco mmons.org/licenses/by/4.0/. The Creative Commons Public Domain Dedication waiver (http://creativecommons.org/publicdomain/ zero/1.0/) applies to the data made available in this article, unless otherwise stated in a credit line to the data. 


\section{Background}

Osteosarcoma is the most common primary malignant bone tumor [1]. It is believed to arise from malignant mesenchymal cells and the pathological process is extremely complex [2-4]. Although conventional treatment options such as chemotherapy and surgery are constantly improving, and new therapies such as targeted therapy and immunotherapy are also appearing, the prognosis of osteosarcoma patients is still poor due to the high degree of malignancy, rapid progression, and chemo-resistance of the disease $[5,6]$. Therefore, it is urgent to elucidate the molecular mechanisms and explore the novel therapeutic strategy of osteosarcoma.

The communication between tumor cells and the corresponding microenvironment is critical for tumor growth and metastasis, and TAMs are the most abundant infiltrating immune cells and play critical roles in the progression of various tumors, including osteosarcoma [7-9]. Activated TAMs can be either antineoplastic (M1) or tumor-promoting (M2), and they often coexist at a dynamic change in a variety of tumors [10]. And our previous study had proved that TAMs could promote lung metastasis and induce epithelial-mesenchymal transition in osteosarcoma by activating the COX-2/STAT3 axis [11]. However, the communication between tumor cells and TAMs is still unclear.

Recently, more and more studies have reported that nano-sized exosomes can be crucial mediators between cellular communication, and cargos like long noncoding RNAs (lncRNAs) could be transported between cells [12, 13]. IncRNA is a type of noncoding RNA that participated in various biological processes in a wide range of human tumors, and a lot of lncRNAs have been reported to act as either oncogenes or tumor suppressors in osteosarcoma [14-16]. Leukemia inhibitory factor receptor antisense RNA 1 (LIFR-AS1) is a novel tumor-related IncRNA and has been reported as a tumor suppressor in breast cancer [17]. However, the role of LIFR-AS1 in osteosarcoma remains unknown.

In this research, we aim to explore the role of macrophages-derived exosomal IncRNA LIFR-AS1 in osteosarcoma development and further elucidated the potential molecular mechanisms involved.

\section{Methods and materials}

\section{Clinical tissue specimen and microarray analysis}

Osteosarcoma and normal bone tissues were acquired from the Musculoskeletal Tumor Center, Peking University People's Hospital (Beijing, China). Informed consent was obtained from all patients and the research was approved by the Ethics Committee of Peking University People's Hospital.

\section{Cell culture and transfection}

The human osteosarcoma cell lines 143B, HOS, MG63, MNNG, Saos2, and U2OS and the human monocytic cell line THP-1 cells were obtained from the American Type Culture Collection (ATCC, Manassas, VA, USA). The 143B, MNNG, and Saos2 cells were cultured in Dulbecco's modified Eagle's medium (DMEM, HyClone) supplemented with $10 \%$ fetal bovine serum (FBS, Gibco), and the HOS, KHOS, U2OS, and MG63 were maintained in RPMI-1640 medium (HyClone) with 10\% FBS. All cells were cultured in a humidified incubator with $5 \% \mathrm{CO} 2$ at $37{ }^{\circ} \mathrm{C}$. Monocyte-differentiated macrophages were induced from THP-1 by treating with $100 \mathrm{ng} / \mathrm{ml}$ PMA for $24 \mathrm{~h}$. Blood samples were donated by healthy volunteers, and peripheral blood mononuclear cells (PBMCs) were isolated using the Human Buffy Coat CD14 Positive Selection Kit (Stemcell) following the manufacturer's protocol.

Besides, si-LIFR-AS1, siNFIA, miR-29a mimic, miR29a inhibitor, and corresponding negative control (NC) were obtained from Gene Pharm (Suzhou, China) and transfected by Lipofectamine 3000 (Invitrogen) according to the instructions provided.

\section{RNA isolation and qRT-PCR}

Total RNA was isolated using TRIzol (Invitrogen) and miRNA was isolated by RNeasy/miRNeasy Mini Kit (Qiagen) according to the manufacturer's instructions. U6 was used as the endogenous control of miRNAs and $\beta$-actin was used as the internal reference of other mRNAs.). The primers used in the experiments are listed in Table 1.

\section{Western blot}

The total protein was isolated using cell lysis buffer and the procedure of western blot was the same as previously described [18]. The following antibodies,

Table 1 Primers for real-time PCR

\begin{tabular}{|c|c|c|}
\hline Primers & & Sequences $\left(5^{\prime}-3^{\prime}\right)$ \\
\hline \multirow[t]{2}{*}{ LIFR-AS1 } & $\mathrm{F}$ & GCAAATACTGTGTATTAGTCC \\
\hline & $\mathrm{R}$ & CCGCTTCCTTGTGAAGAAGGT \\
\hline \multirow[t]{2}{*}{ NFIA } & $\mathrm{F}$ & TAATCCAGGGCTCTGTGTCC \\
\hline & $\mathrm{R}$ & CCTGCAGCTATTGGTGTCTG \\
\hline \multirow[t]{2}{*}{$\beta$-actin } & $\mathrm{F}$ & GTCAGGTCATCACTATCGGCAAT \\
\hline & $\mathrm{R}$ & AGAGGTCTTTACGGATGTCAACGT \\
\hline \multirow[t]{2}{*}{ miR-29a } & $\mathrm{F}$ & 5'-GGGTAGCACCATCTGAAAT-3' \\
\hline & $\mathrm{R}$ & CAGTGCGTGTCGTGGAGT \\
\hline \multirow[t]{2}{*}{ U6 } & $\mathrm{F}$ & CTCGCTTCGGCAGCACA \\
\hline & $\mathrm{R}$ & AACGCTTCACGAATTTGCGT \\
\hline
\end{tabular}


anti-cleaved-PARP, anti-E-cadherin, anti-N-cadherin were obtained from Cell Signaling Technology, antiBcl-2, anti-Bax, anti-NFIA were obtained from Proteintech, and anti-CD9, anti- CD63, and anti- $\beta$-actin were obtained from Santa Cruz.

\section{Dual-luciferase reporter gene assay}

The $3^{\prime}$-UTR fragments of wild-type/mutated NFIA or LIFR-AS1 were cloned into the pmirGLO luciferase reporter vector. Then, they were co-transfected into $293 \mathrm{~T}$ cells with miR-29a mimic/NC. Dual-Luciferase Reporter Assay System (E191, Promega) was used to detect the luciferase activity and the results are expressed as firefly luciferase activity normalized to Renilla luciferase activity.

\section{Flow cytometry (FCM)}

For apoptosis, cells were collected after $24 \mathrm{~h}$ of culture and stained with the Annexin V/FITC Kit (BD Biosciences) according to the guidelines provided. And then, flow cytometry was used to analyze apoptosis.

\section{Wound-healing and transwell assay}

For the wound-healing assay, cells were added in 6-well plates and cultured in an incubator. When the confluency reached $70-80 \%$, artificial wounds were made by $\mathrm{P}-200$ pipette tips. The images of $0 \mathrm{~h}$ and $24 \mathrm{~h}$ were acquired under a phase-contrast microscope.

For transwell assay, $600 \mu \mathrm{l}$ complete medium was added into the lower chambers of transwell plates (BD Biosciences). And then $5 \times 10^{4}$ cells in $200 \mu \mathrm{l}$ FBS-free medium were seeded into the matrigel-coated or noncoated upper chambers. After $24 \mathrm{~h}$, the medium was discarded and cells were fixed with $4 \%$ paraformaldehyde for $20 \mathrm{~min}$, then washed with PBS and stained with $0.1 \%$ crystalline violet solution for analyzing under a microscope.

\section{Exosomes extraction and exosome uptake assay}

Cells were incubated in an exosome-free medium for $48 \mathrm{~h}$ and the culture supernatants were collected to centrifuged as following steps: $300 \times g$ for $10 \mathrm{~min}$ to remove cells, $2000 \times g$ for $10 \mathrm{~min}$ to remove dead cells, $10,000 \times g$ for $30 \mathrm{~min}$ to remove cell debris, $100,000 \times g$ for $70 \mathrm{~min}$ to collect pellets and washed with PBS, $100,000 \times g$ for 70 min to collect exosomes.

PKH26 Fluorescent Cell Linker Kits (Sigma) was used to label macrophage-derived exosomes according to the manufacturer's instructions. Then, PKH26-labeled exosomes were added into osteosarcoma cells and the uptake process was recorded by a confocal fluorescence microscope.

\section{Cck-8, colony formation and EdU assay}

For the cck- 8 assay, $5 \times 10^{3}$ cells were seeded into 96-well plates. And cell viability was examined daily for 3 days using CCK-8 (Dojindo Laboratories, Japan) according to the instruction provided.

For colony formation assay, 800 cells were seeded into 12-well plates and cultured for 4-5 days. Then, the medium was discarded and cells were fixed with $4 \%$ paraformaldehyde for $20 \mathrm{~min}$, washed with PBS, and stained with $0.1 \%$ crystalline violet solution for analysis.

For EdU assays, $5 \times 10^{3}$ cells were seeded into 96-well plates and EdU Apollo 567 Cell Tracking Kit (RiboBio, China) was used according to the instruction provided. And cell nucleus was stained with DAPI.

\section{Tumor xenografts}

$22 \mathrm{BALB} / \mathrm{c}$ nude mice were purchased from Vital River (Beijing, China). For tumor xenograft models, $5 \times 10^{6}$ $143 \mathrm{~B}$ cells were subcutaneously injected in the right flank of 6 mice, and after 3 days, THP-1 induced macrophagederived exosomes $(1 \mathrm{mg} / \mathrm{kg}$ in $100 \mu \mathrm{l}$ PBS $)$ or PBS was locally injected into the tumor mass once every 3 days for 5 times. The tumor volume (length $\times$ width $^{2} / 2$ ) was recorded every 3 days and the mice were sacrificed after 15 days. Furthermore, we repeated the animal experiment using peripheral blood mononuclear cells (PBMCs) derived macrophage in another 10 mice $(5$ mice per group).

For lung metastasis models, $2 \times 10^{6} 143 \mathrm{~B}$ cells were intravenously injected in the tail vein of 6 mice. Then, macrophages-derived exosomes $(1 \mathrm{mg} / \mathrm{kg}$ in $100 \mu \mathrm{l} \mathrm{PBS})$ or PBS were injected into the tail vein of mice once every 3 days for 5 times. The mice were sacrificed after 15 days and lungs were collected for further research.

All animal experiments were performed with written confirmation authorized by the Animal Care and Use Committee of Peking University People's Hospital. Animal experiments complied with the ARRIVE guidelines and followed the National Institutes of Health Guide for the Care and Use of Laboratory Animals.

\section{Statistical analysis}

SPSS 21.0 software was used for statistical analyses and data were presented as the mean $\pm \mathrm{SD}$. Differences between groups were analyzed by Student's t-test.

\section{Result}

Macrophages promote the proliferation and invasion but inhibit apoptosis of osteosarcoma cells

After THP-1-induced macrophages were incubated in a serum-free medium for $24 \mathrm{~h}$, the culture supernatants were collected as conditioned medium (M $\phi-\mathrm{CM})$. Then, 
osteosarcoma cells were co-cultured with CM, and functional assays were performed to investigate the effects of macrophages on osteosarcoma cells. The cck- 8 assay results showed that $\mathrm{M} \phi-\mathrm{CM}$ significantly facilitated the proliferation of osteosarcoma cell lines 143B and U2OS (Fig. 1a), and the colony formation assay (Fig. 1b) and EdU assay (Fig. 1c) showed the same results. However, flow cytometry results showed that $\mathrm{M} \phi-\mathrm{CM}$ significantly inhibited the apoptosis of osteosarcoma cells (Fig. 1d), which indicated $\mathrm{M} \phi-\mathrm{CM}$ might promote cell proliferation by restrain apoptosis in osteosarcoma. Besides, wound-healing assay results showed $\mathrm{M} \phi-\mathrm{CM}$ could promote the migration of $143 \mathrm{~B}$ and U2OS cells (Fig. 1e). And then, the transwell assays verified that both migration ability and invasion ability of osteosarcoma cells were increased by $\mathrm{M} \phi-\mathrm{CM}$ (Fig. 1f-g). Then, we verified
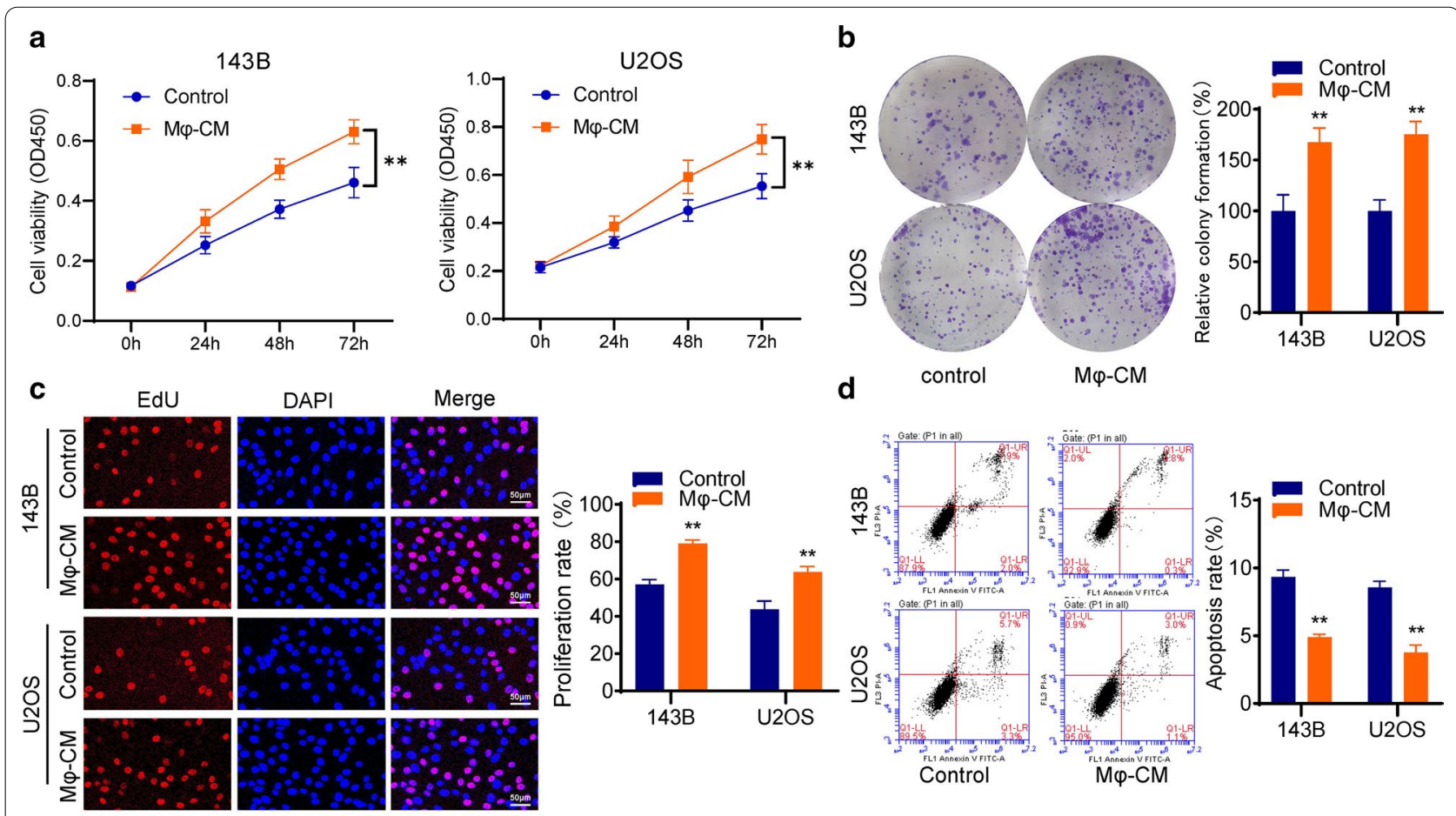

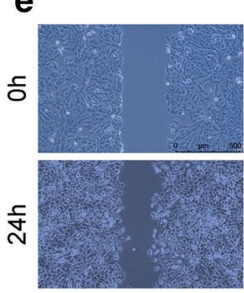

Control

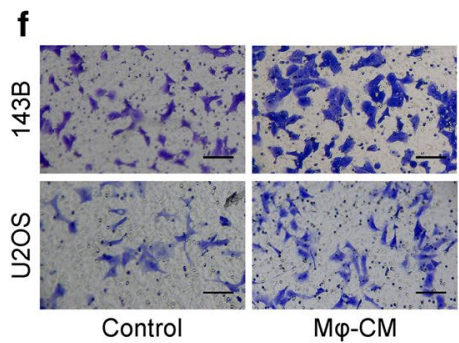

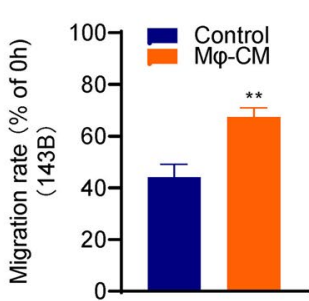

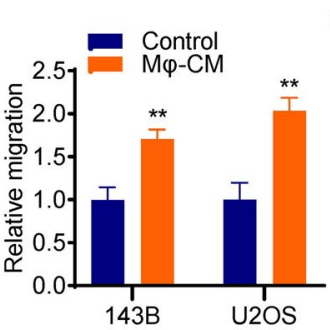

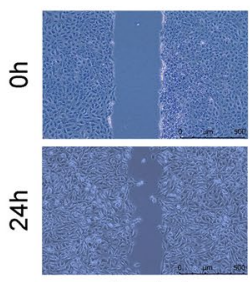

Control

\section{g}

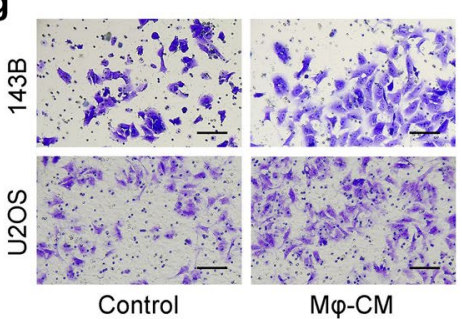

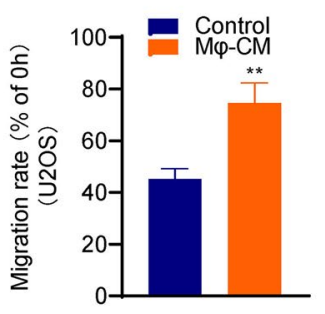

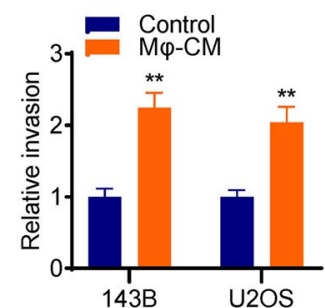

Fig. 1 Macrophages promote the proliferation and invasion but inhibit apoptosis of osteosarcoma cells. a The cck-8 assay for cell proliferation. b Colony formation assay. c EdU assay for cell proliferation. d Flow cytometry was used to detect the apoptosis of osteosarcoma cells. e Wound-healing assay results showed $\mathrm{M} \varphi$-CM could promote the migration of $143 \mathrm{~B}$ and U2OS cells. $\mathbf{f}-\mathbf{g}$ Transwell assays indicated that macrophages could promote both migration and invasion of osteosarcoma cells. ${ }^{* *} p<0.01$ 
the results using peripheral blood mononuclear cells (PBMCs) derived macrophage, which showed the same tumor-promoting action as THP-1 induced macrophages (Additional file 1: Figure S1).

\section{LncRNA LIFR-AS1 is highly expressed in $\mathrm{M} \varphi$-CM co-cultured osteosarcoma cells and acts as a sponge for miR-29a}

RNA-sequencing was used to identify the differentially expressed miRNAs and lncRNAs in $\mathrm{M} \phi-\mathrm{CM}$ co-cultured osteosarcoma cells and the corresponding control group. As showed in Fig. 2a-b, lowly expressed miR-29a was observed in $\mathrm{M} \phi-\mathrm{CM}$ co-cultured osteosarcoma cells compared with the control group. Then, the ENCORI database was used to predict target lncRNAs of miR-29a, and highly expressed LIFR-AS1 was the only intersecting gene between predicted target lncRNAs and differentially expressed lncRNAs (Fig. 2c-e). To investigate the interaction between LIFR-AS1 and miR-29a, a dual-luciferase reporter assay was performed and the results showed that miR-29a mimic significantly reduced luciferase activity in LIFR-AS1 wild type (WT), but not mutant (MUT), verifying the direct binding between LIFR-AS1 and miR-29a (Fig. 2f-g). Furthermore, we found that lncRNA LIFR-AS1 was highly expressed and miR-29a was lowly expressed in osteosarcoma tissues compared with normal tissues, and there is a negative correlation between their expression (Fig. $2 \mathrm{~h}-\mathrm{j}$ ). The same result was observed in osteosarcoma cell lines when compared with human osteoblast cell line hFOB (Fig. 2k-l). Besides, the ENCORI database revealed that there was a significant positive correlation between miR-29a expression and overall survival ( $\mathrm{p}=0.018$ ) (Fig. $2 \mathrm{~m}$ ).

To further confirm the function of LIFR-AS1 in tumorigenesis. We directly overexpressed lncRNA LIFR-AS1 in osteosarcoma cells and found that overexpressed LIFRAS1 can significantly promote proliferation and invasion of osteosarcoma cells. Furthermore, miR-29a overexpression can rescue the effects of LIFR-AS1 overexpression (Fig. 2n-q).

\section{LIFR-AS1 can be transmitted from macrophages to osteosarcoma cells via exosomes}

macrophages-derived exosomes ( $\mathrm{M} \phi$-Exos) were extracted using ultracentrifugation, and the exosome identification was performed by transmission electron microscopy (TEM), Nanoparticle Tracking Analysis (NTA), and western blot. Under TEM, M $\phi$-Exos were observed as a bowl-shaped bilayer membrane structure with diameters range of around $100 \mathrm{~nm}$ (Fig. 3a). NTA results showed that $\mathrm{M} \phi$-Exos were located predominately around $100 \mathrm{~nm}$, which was consistent with the TEM result (Fig. 3b). Western blot results confirmed that exosome surface marker proteins CD9 and CD63 could be detected in $\mathrm{M} \phi$-Exos (Fig. 3c). Then, an exosome uptake assay was performed and the transport processes of exosomes could be observed under a confocal fluorescence microscope (Fig. 3d). Furthermore, two siRNA sequences were used to knock down the expression of LIFR-AS1 in macrophages, and the results showed that LIFR-AS1 was significantly downregulated by siRNAs in both macrophages and $M \phi$-Exos (Fig. 3e), and the same results were observed in $\mathrm{M} \phi$-Exos cocultured osteosarcoma cells (Fig. 3f). Besides, after co-cultured for $24 \mathrm{~h}$, qRT-PCR results showed that miR-29a was significantly downregulated by $\mathrm{M} \phi$-Exos in osteosarcomas, and this effect was attenuated when LIFR-AS1 was knocked down in M $\phi$-Exos. And, miR29a inhibitor could significantly downregulate the expression of miR-29a in both osteosarcoma cells and $\mathrm{M} \phi$-Exos co-cultured osteosarcoma cells (Fig. 3g-h). We further detected the expression of miR-29a in both macrophage cells and exosomes after lncRNA LIFR-AS knockdown in macrophages (Additional file 1: Figure S3). And the result showed that LIFR-AS knockdown can significantly upregulated the expression of miR29a in macrophages cells but not in exosomes, which could be attributed to the selective encapsulation of exosomes.

\footnotetext{
(See figure on next page.)

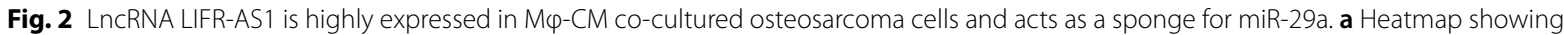
the differentially expressed miRNAs. $\mathbf{b}$ the expression of miR-29a was verified using qRT-PCR. $\mathbf{c}$ Heatmap representing the differentially expressed InCRNAs. d LIFR-AS1 was the only intersecting gene between predicted target IncRNAs of miR-29a and differentially expressed IncRNAs. e The expression of LIFR-AS1 was verified using qRT-PCR. $\mathbf{f}$ Schematic representation of the binding site between LIFR-AS1 and miR-29a. $\mathbf{g}$ The dual-luciferase reporter assay verified the direct binding between LIFR-AS1 and miR-29a. $\mathbf{h}-\mathbf{j}$ LIFR-AS1 was highly expressed and miR-29a was lowly expressed in osteosarcoma tissues, and negatively correlated. k-IThe expression of LIFR-AS1 and miR-29a was detected in osteosarcoma cell lines and hFOB. $\mathbf{m}$ ENCORI database revealed that there was a significant positive correlation between miR-29a expression and overall survival. $\mathbf{n}-\mathbf{o}$ The expression of LIFR-AS1 and miR-29a in osteosarcoma cells. $\mathbf{p}-\mathbf{q}$ Overexpressed LIFR-AS1 can significantly promote proliferation and invasion of osteosarcoma cells, but miR-29a overexpression can rescue its effects. oe-LIFR-AS1: LIFR-AS1 overexpressed; oe-LIFR-AS1 + mimic NC: co-transfecting LIFR-AS1 overexpressed plasmid and miRNA mimics NC; oe-LIFR-AS1 + miR-29a mimic: co-transfecting LIFR-AS1 overexpressed plasmid and miR-29a mimic. ${ }^{*} p<0.05,{ }^{* *} p<0.01$
} 

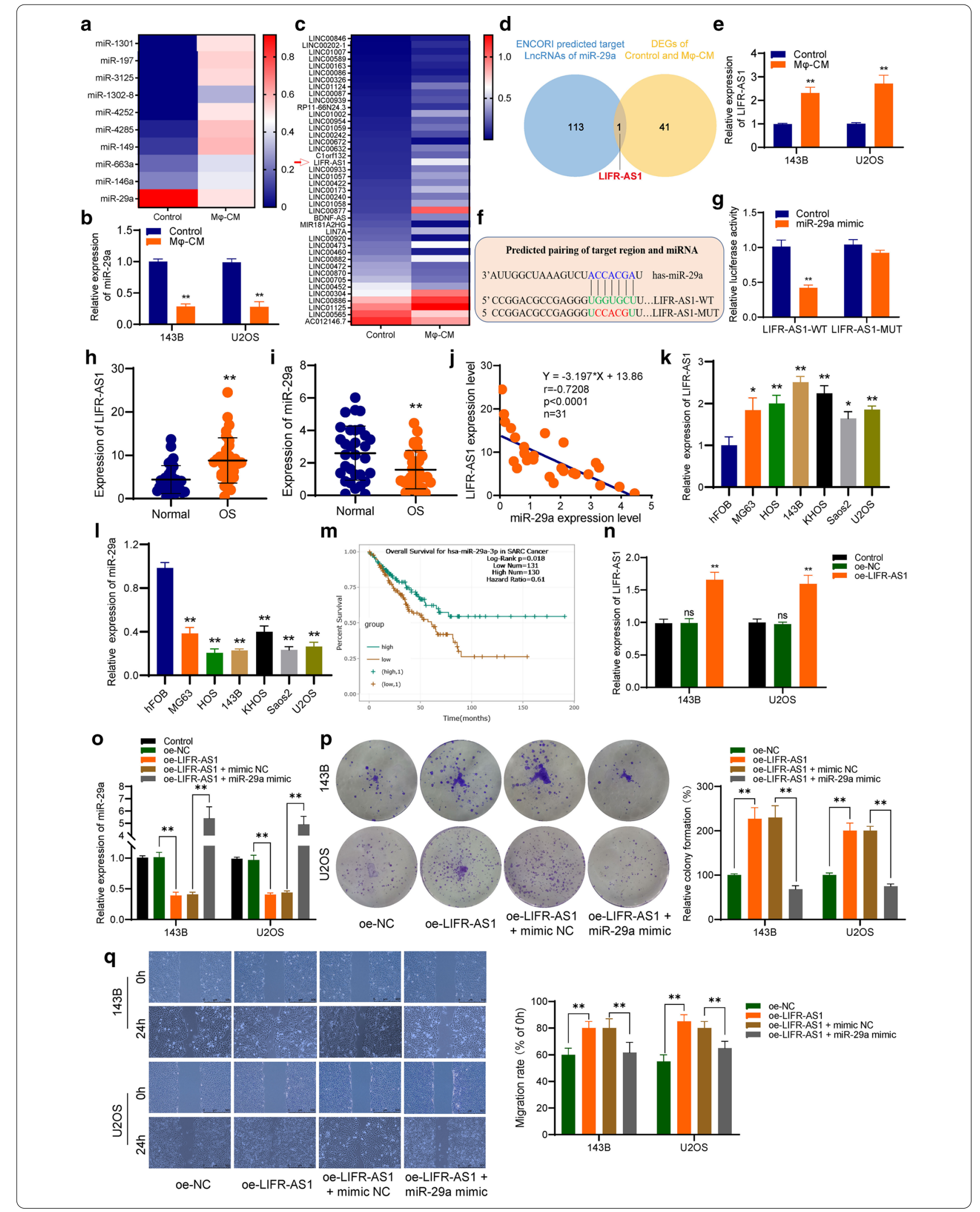

e 

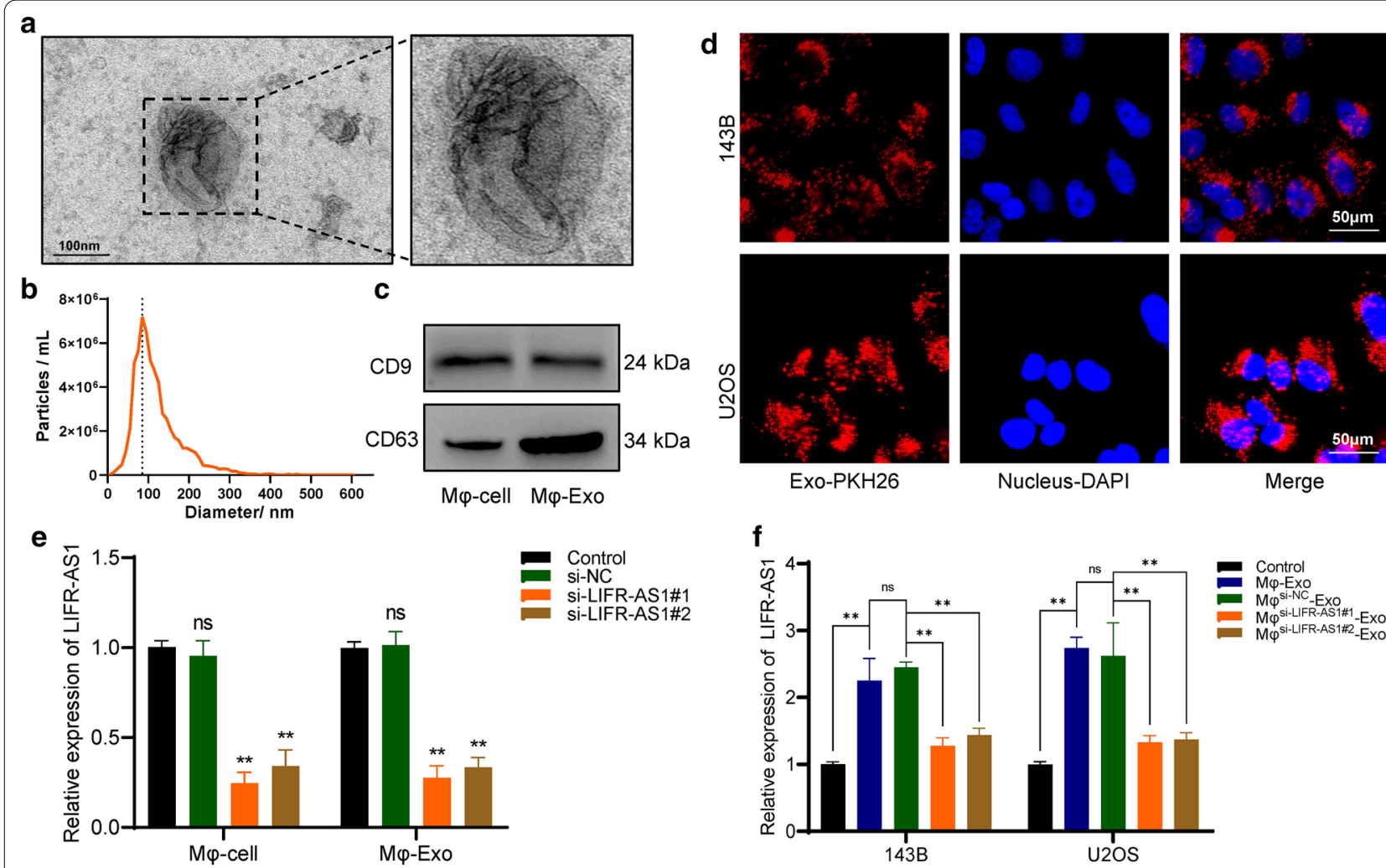
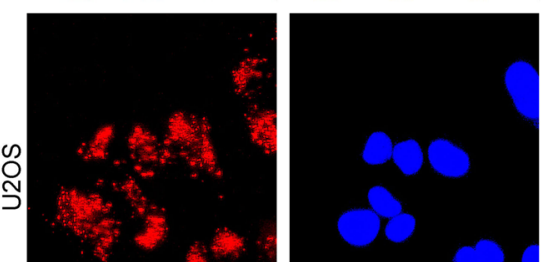

Nucleus-DAPI

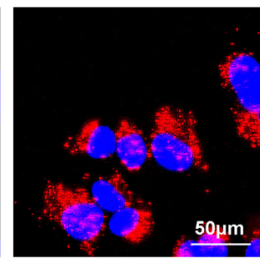

Exo-PKH26

f

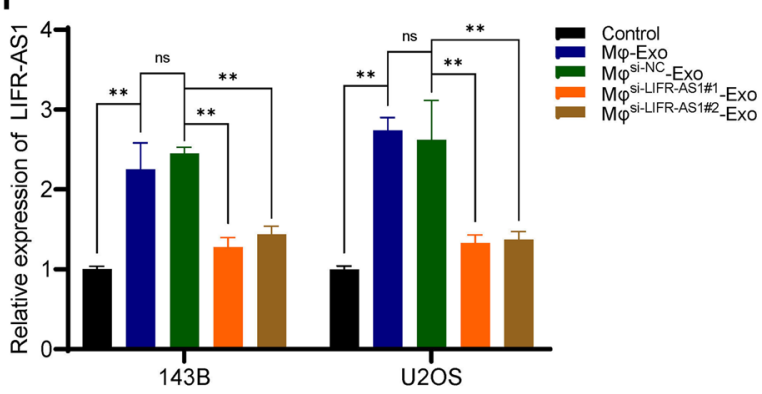

g

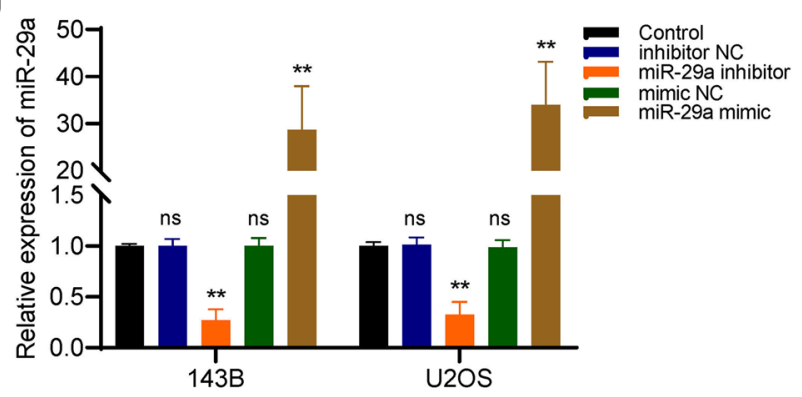

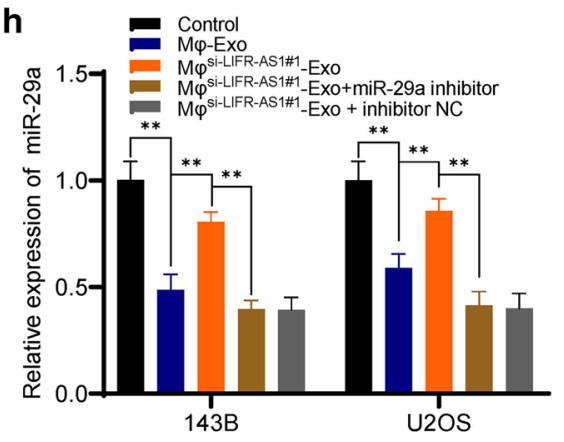

Fig. 3 LIFR-AS1 can be transmitted from macrophages to osteosarcoma cells via exosomes. a Representative image of exosomes under TEM. $\mathbf{b}$ NTA results showed that M $\varphi$-Exos were located predominately around $100 \mathrm{~nm}$. c Exosome surface marker proteins CD9, CD63 was detected by western blot. $\mathbf{d}$ Macrophages-derived exosomes were ingested by 143B cells. e LIFR-AS1 was knocked down by siRNAs in both macrophages and $\mathrm{M} \varphi$-Exos. $\mathbf{f}$ The expression of LIFR-AS1 in M $\varphi$-Exos co-cultured osteosarcoma cells. $\mathbf{g}$ The expression of miR-29a can be regulated by miR-29a mimics

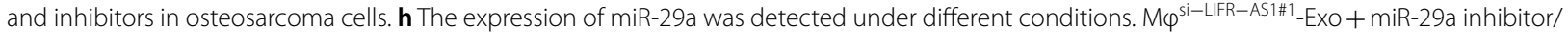

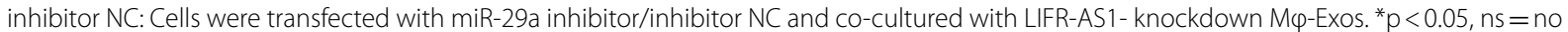
significant

\section{Macrophages-derived exosomal LIFR-AS1 promotes osteosarcoma cell progression via sponging miR-29a}

Both cck-8 and colony formation assays results showed that $\mathrm{M} \phi$-Exos significantly promoted osteosarcoma cell proliferation, and the promoting effect was attenuated when LIFR-AS1 was knocked down in M $\phi$-Exos $\left(\mathrm{M} \phi^{\text {si-LIFR-AS1 }}\right.$-Exo). However, miR-29a inhibitor could partially reverse the effect of $M \phi^{\text {si-LIFR-AS1 }}$-Exo on osteosarcoma cells (Fig. 4a-b). Flow cytometry results showed that $\mathrm{M} \phi$-Exos suppressed osteosarcoma cells apoptosis, and miR-29a inhibitor could partially recover LIFR-AS1-knockdown caused effect on osteosarcoma cells (Fig. 4c). Similarly, the results of the wound-healing assay and transwell assay demonstrated that $\mathrm{M} \phi$-Exos significantly enhanced the migration and invasion abilities of osteosarcoma cells, and miR-29a inhibitor had the opposite effect with macrophagesderived exosomal LIFR-AS1 (Fig. 4d-f). Furthermore, 

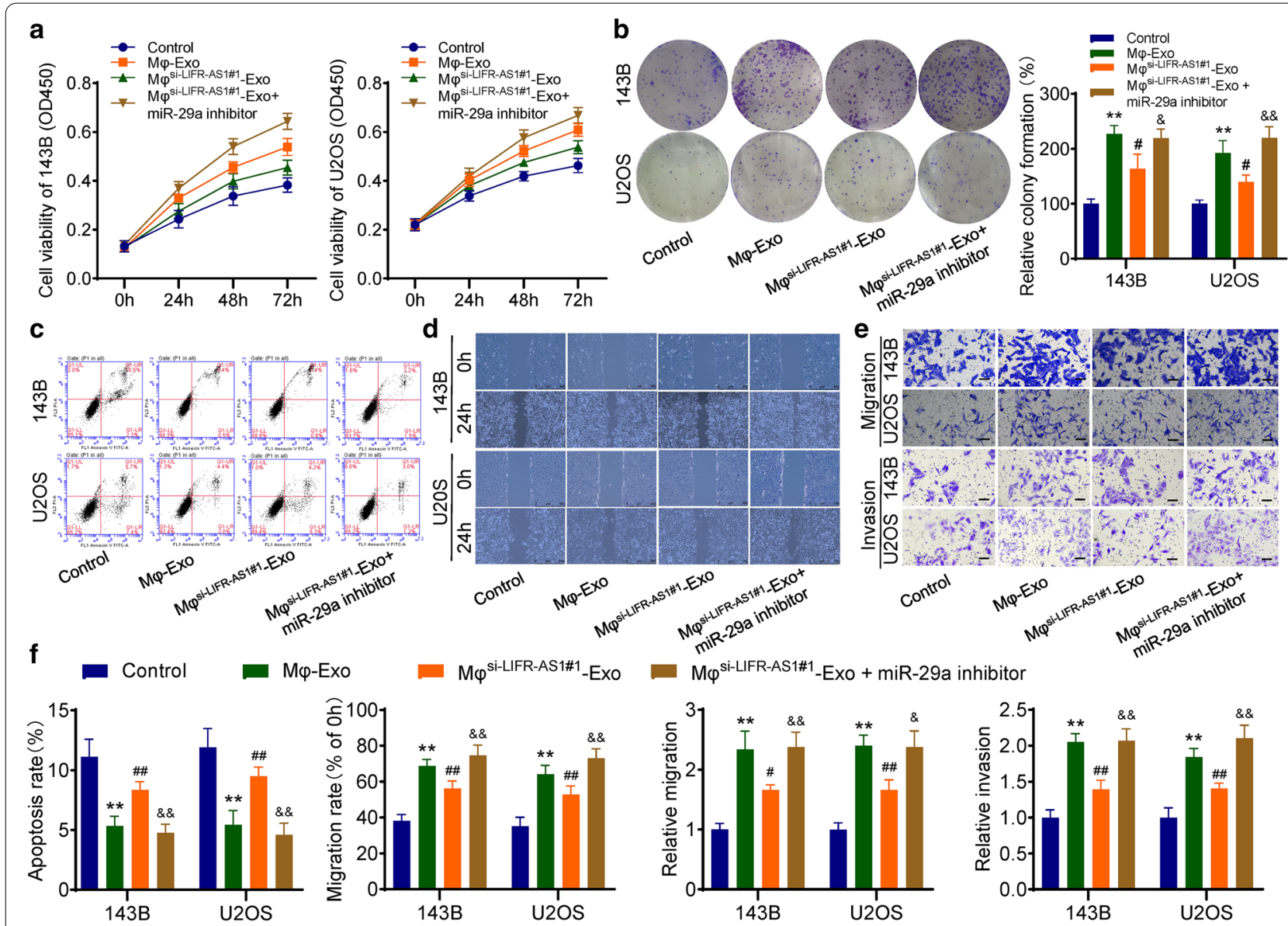

$M \varphi^{\text {Si-LIFR-AS1\#1 }-E x O}$

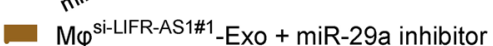

g
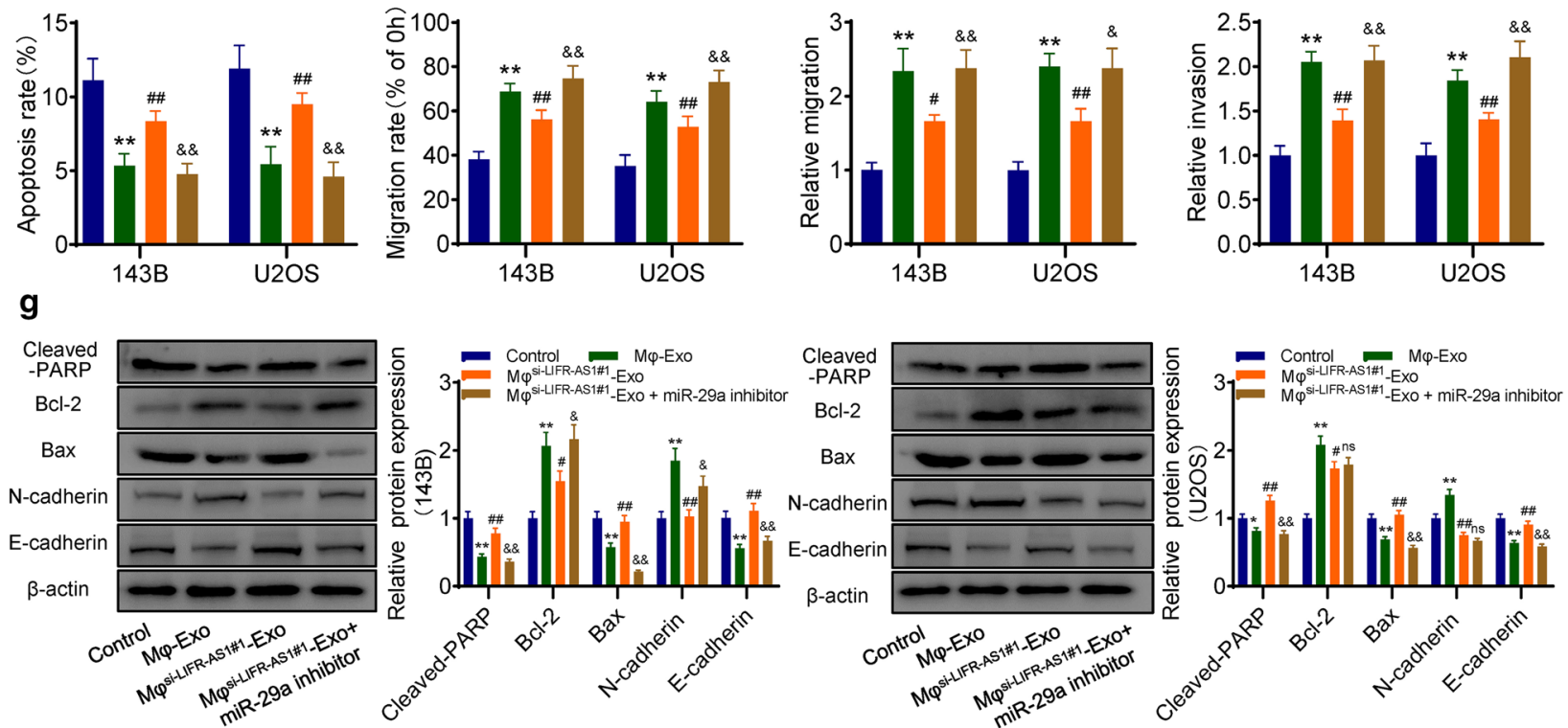

Fig. 4 Macrophages-derived exosomal LIFR-AS1 promotes osteosarcoma cell progression via sponging miR-29a. a The cck-8 assay for cell proliferation. b Colony formation assay. c Flow cytometry for apoptosis. $\mathbf{d}$ Wound-healing assay. e Transwell assays for migration and invasion. $\mathbf{f}$ Statistical results of apoptosis, wound-healing, and transwell assays are showing accordingly. $\mathbf{g}$ The expression levels of apoptosis-related and EMT-related proteins were detected by western blot. M $\varphi^{\text {Si-LIFR-ASI\#1 }-E X O}+$ miR-29a inhibitor: Cells were transfected with miR-29a inhibitor/inhibitor $\mathrm{NC}$ and co-cultured with LIFR-AS1- knockdown M $\varphi$-Exos. ${ }^{*} p<0.05$, ${ }^{* *} p<0.01$, compared with control group; \#p $<0.05$, \#\#p $<0.01$, compared with

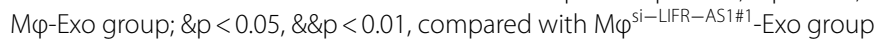

we detected the apoptosis and epithelial-mesenchymal transition (EMT) associated proteins in osteosarcoma cells via western blot, and the results showed that $M \phi$-Exos significantly inhibited the expression of apoptosis protein cleaved-PARP, Bax, and EMT marker E-cadherin, but promoted the expression of anti-apoptosis protein $\mathrm{Bcl}-2$, and EMT marker $\mathrm{N}$-cadherin. However, exosomal LIFR-AS1-knockdown attenuated the regulating effect of $\mathrm{M} \phi$-Exos on osteosarcoma cells, and miR-29a inhibitor could partially recover it (Fig. 4g). Taken together, all these results indicated that macrophages could promote osteosarcoma cell 
progression via exosomal LIFR-AS1, which could act as a sponge for miR-29a in osteosarcoma cells.

\section{NFIA is the direct target gene of miR-29a}

Five bioinformatics tools (RNA22, micro T, TargetScan, PicTar, and miRanda) were used to predict the target gene of miR-29a, and nuclear factor I/A (NFIA) was identified as a possible target gene according to the prediction score and publications (Fig. 5a). Then, the expression of NFIA protein was detected by western blot, and the result indicated that NFIA was highly expressed in osteosarcoma cell lines (143B, HOS, MG63, MNNG, Saos2 and U2OS) compared with human osteoblast cell Line hFOB (Fig. 5b-c). Furthermore, the direct binding between miR-29a and NFIA was verified by dual-luciferase reporter assay (Fig. $5 \mathrm{~d}-\mathrm{e}$ ). And the result of western blot confirmed that NFIA protein expression could be regulated by miR-29a (Fig. 5f).

miR-29a inhibited the proliferation and invasion but induced apoptosis of osteosarcoma cells via targeting NFIA

Two siRNA sequences were transfected into osteosarcoma cells, and the knockdown effect was observed in both mRNA and protein levels (Fig. 6a-b). The results of cck-8 (Fig. 6c-d), colony formation (Fig. 6e) and EdU assays (Fig. 6f) showed that miR-29a significantly inhibited the proliferation of osteosarcoma cells, and NFIA-knockdown could partially reverse miR-29a inhibitor-mediated cell proliferation promotion. Flow cytometry results showed that miR-29a could induce apoptosis of osteosarcoma cells, and NFIA-knockdown could recover miR-29a inhibitor-mediated apoptosis inhibition (Fig. 6g). Besides, the results of the woundhealing assay and transwell assay demonstrated that miR29a significantly inhibited the migration and invasion abilities of osteosarcoma cells, and NFIA-knockdown could recover miR-29a inhibitor-mediated cell migration promotion and invasion promotion (Fig. $6 \mathrm{~h}$ and i). Furthermore, western blot results showed that miR-29a significantly inhibited the expression of NFIA, antiapoptosis protein $\mathrm{Bcl}-2$, and EMT marker $\mathrm{N}$-cadherin, but promoted the expression of pro-apoptotic protein Bax and EMT marker E-cadherin in osteosarcoma cells. However, miR-29a inhibitor showed opposite regulation on these proteins and could be reversed by NFIA-knockdown (Fig. 6j).

\section{NFIA is highly expressed in pulmonary metastasis focuses of osteosarcoma patient}

The expression of NFIA was examined in human primary osteosarcoma tissue and corresponding lung metastases $(n=10$ pairs), and the result showed that NFIA was expressed more strongly in pulmonary metastasis focuses (Fig. 7a-b).

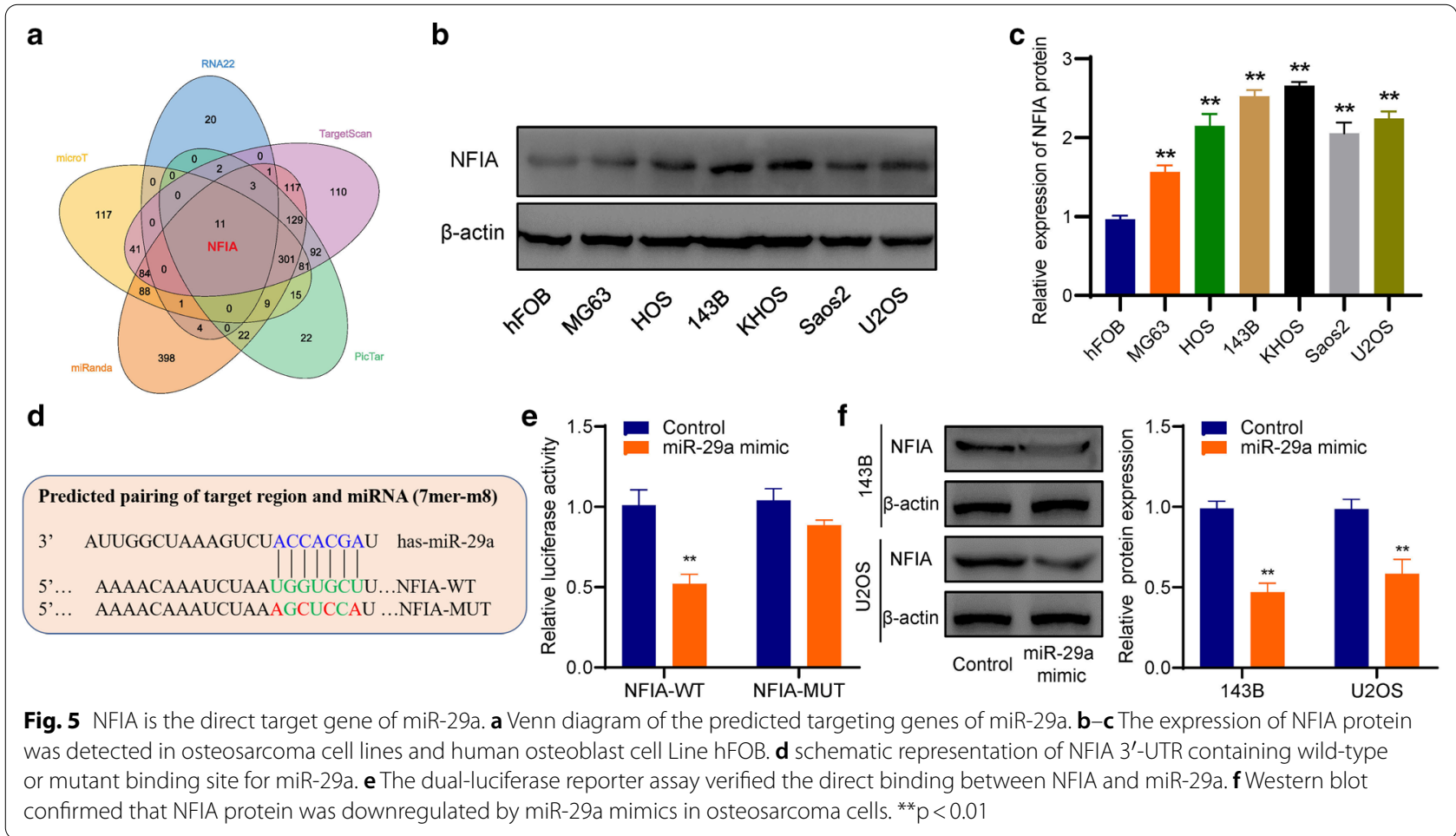




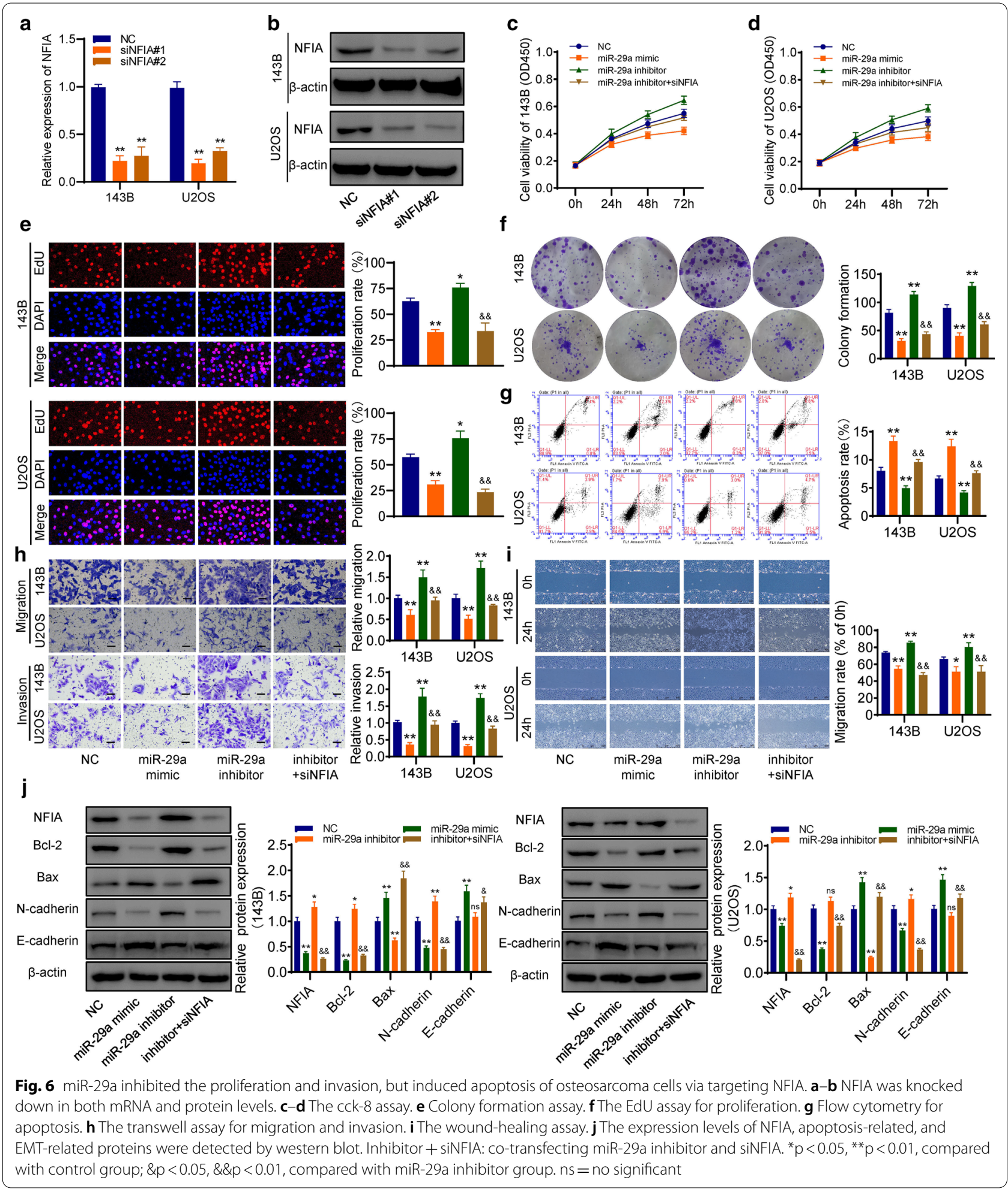

Macrophages-derived exosomes promote osteosarcoma growth and metastasis in vivo

The effect of $\mathrm{M} \phi$-Exos on the growth of tumors was detected on xenograft in nude mice, and the results indicated that $M \varphi$-Exos significantly promoted the growth rate and increased the tumor weight of osteosarcoma 

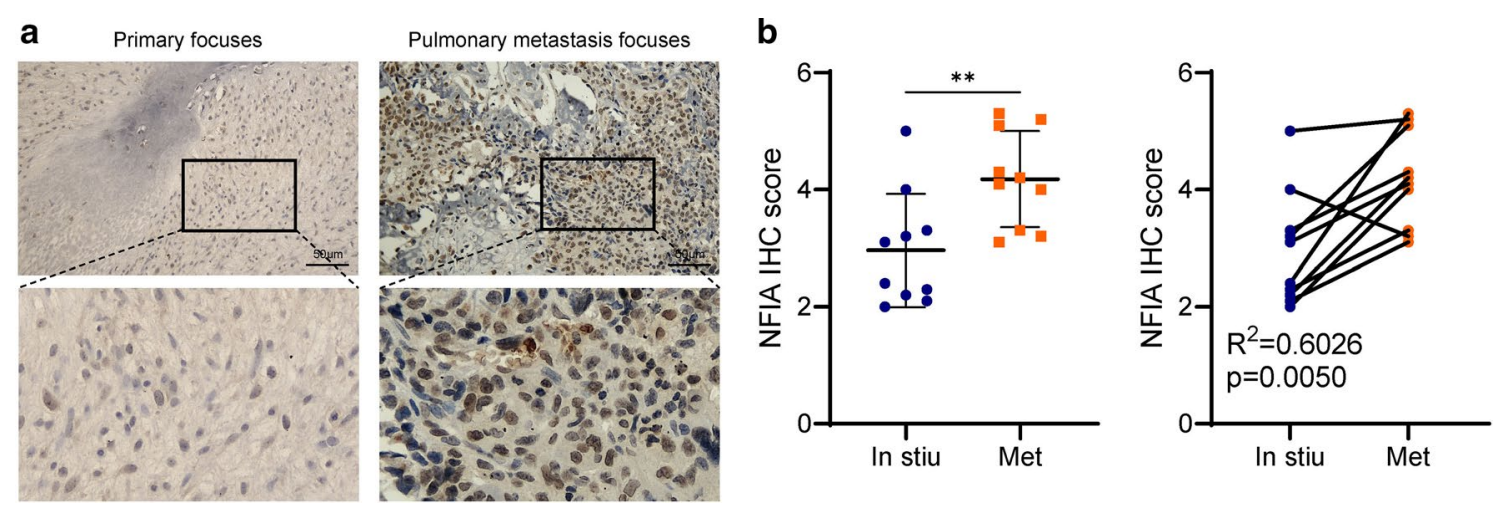

Fig. 7 NFIA is highly expressed in pulmonary metastasis focuses of osteosarcoma patient. a Representative image of $I H C$ result. $\mathbf{b} \| \mathrm{HC}$ result showed that NFIA was expressed more strongly in pulmonary metastasis focuses. ${ }^{* *} \mathrm{p}<0.01$

(Fig. 8a-c, and Additional file 1: Figure S2). Then, the lung metastasis model was established via a tail vein injection of osteosarcoma cells, and more metastatic tumor nodules were observed in the $\mathrm{M} \phi$-Exos group compared with the control group (Fig. 8d-f). Furthermore, IHC was performed to detect the expression of related proteins, and the result indicated that the tumors of the M $\phi$-Exos group expressed more $\mathrm{Ki}-67, \mathrm{~N}$-cadherin, Vimentin, and NFIA, but less E-cadherin than those of the control group (Fig. 8g).

\section{Discussion}

Osteosarcoma patients often have a poor prognosis due to the rapid progression and lack of effective therapy [19]. Macrophages, as the most abundant infiltrating immune cells in the tumor microenvironment, play a pivotal role in tumorigenesis, tumor development, and tumor therapy [20]. Recently, more and more studies indicate that macrophages invade massively osteosarcoma tissues and appear to play a crucial role in the development of osteosarcoma [21]. However, due to the infiltration and polarization of macrophages are dynamically changed in tumors, the function of macrophages in osteosarcoma is also inconsistent [11]. Buddingh et al. demonstrated that the total number of tumor-infiltrating macrophages was related to metastasis suppression but M2 macrophages were associated with poor prognosis in high-grade osteosarcoma [22]. Zhou et al. reported that M2 macrophages promote pulmonary metastasis of osteosarcoma [23]. And our previous study revealed that macrophages contribute to metastasis and invasion in osteosarcoma patients [11].

On the other hand, the specific communication mechanism between macrophages and osteosarcoma cells is still largely unclear. Su et al. reported that macrophagederived CCL18 promotes osteosarcoma proliferation and migration by upregulating the expression of UCA1 [24]. In the previous study, we found that macrophages CM could promote the progression of osteosarcoma cells [11]. And in this study, we further confirm that $\mathrm{M} \phi-\mathrm{CM}$ can regulate several processes of osteosarcoma, including proliferation, invasion, migration, and apoptosis etc.

To further explore the specific molecular mechanisms, in this report, we use RNA-sequencing to identify the differentially expressed miRNAs and lncRNAs in $\mathrm{M} \phi-\mathrm{CM}$ co-cultured osteosarcoma cells and the corresponding control group, and lowly expressed miR-29a is observed in $\mathrm{M} \phi-\mathrm{CM}$ co-cultured osteosarcoma cells. Furthermore, we confirm that lncRNA LIFR-AS1 is upregulated in $\mathrm{M} \phi-\mathrm{CM}$ co-cultured osteosarcoma cells and can act as a sponge of miR-29a. Emerging studies have suggested that exosomes can act as a crucial mediator between cellular communication by transporting cargos like lncRNAs [25, 26]. In this study, we also demonstrate that LIFR-AS1 can be transmitted from macrophages to osteosarcoma cells via exosomes and further promote the tumor progression via sponging miR-29a.

LIFR-AS1 is a newly described tumor-related lncRNA and can serve as a competitive endogenous RNA (ceRNA) for several miRNAs. Wang et al. reported that LIFR-AS1 was lowly expressed in breast cancer and associated with poor prognosis [27]. Zhu et al. revealed that LIFR-AS1 could be a potential therapeutic target as well as a prognostic biomarker of clear cell kidney carcinoma [28]. Also, Liu et al. reported that LIFR-AS1 modulates the resistance of colorectal cancer to photodynamic therapy via the miR-29a/ TNFAIP3 axis [29].

Besides, lots of studies have demonstrated that dysregulated miRNAs were vital regulators in the development of various tumors [18]. And miR-29a is a widely researched miRNA, it can act as either oncogene or tumor suppressor in a variety of tumors [30]. In the 

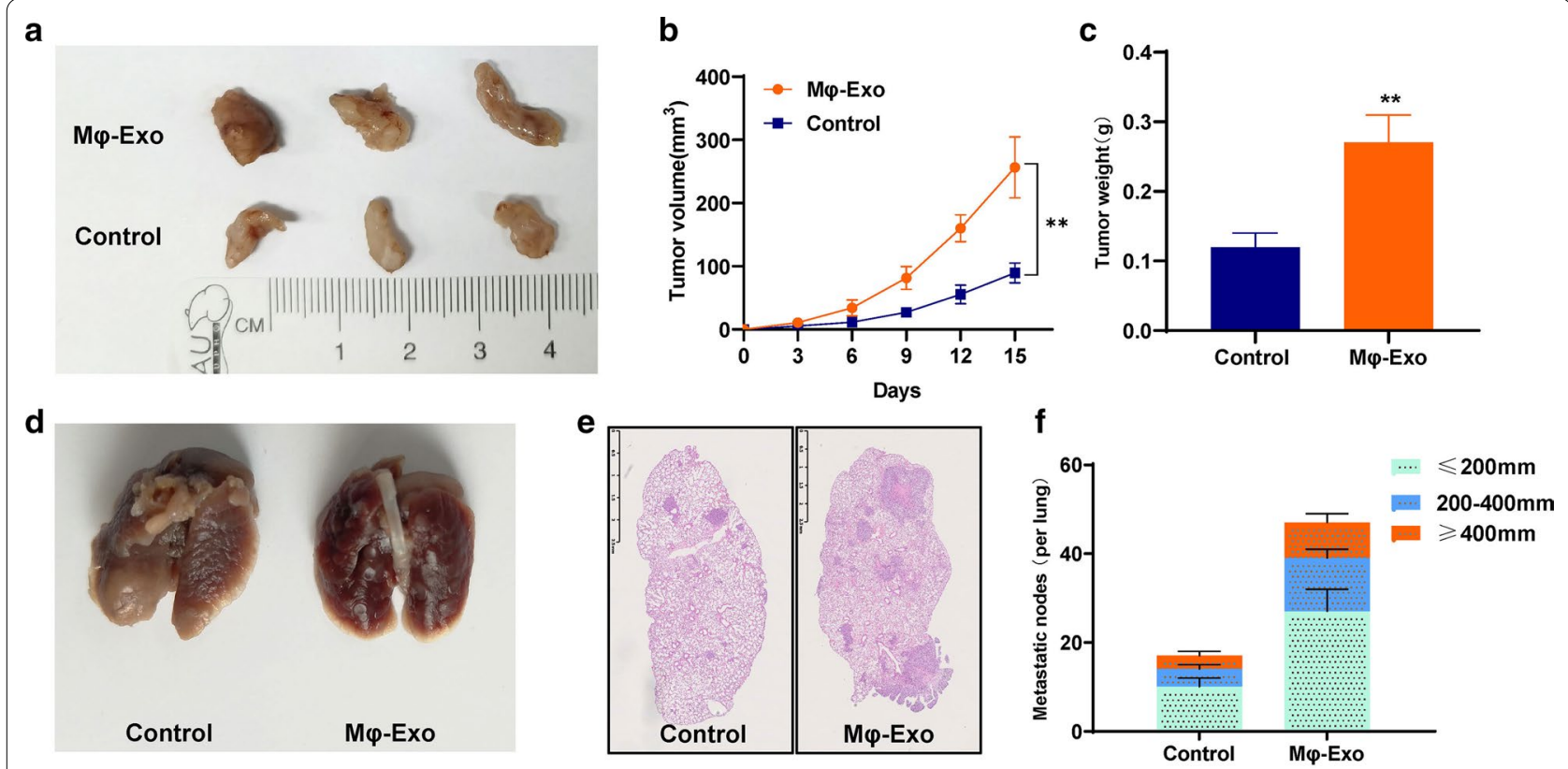

g

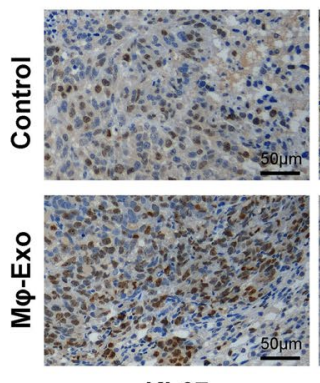

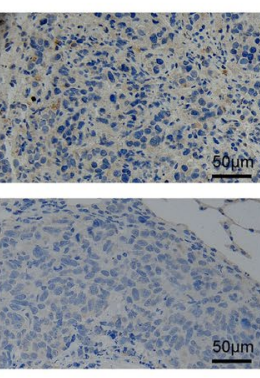

E-cadherin

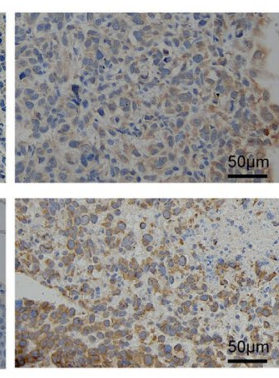

$\mathrm{N}$-cadherin

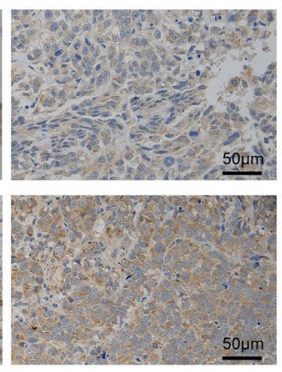

Vimentin

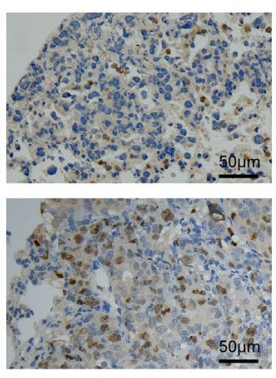

NFIA

Fig. 8 Macrophages-derived exosomes promote osteosarcoma growth and metastasis in vivo. a The effect of M $\varphi$-Exos on the growth of tumors was detected on xenograft. $\mathbf{b}$ The growth curve of xenograft. c The tumor weight of xenograft. $\mathbf{d}$ The lung metastasis model was established via a tail vein injection of osteosarcoma cells. $\mathbf{e}-\mathbf{f}$ Metastatic tumor nodules were observed by H\&E staining. $\mathbf{g} \| \mathrm{HC}$ was performed to detect the expression of proteins. ${ }^{* *} \mathrm{p}<0.01$

present study, we find that miR-29a is lowly expressed in osteosarcoma tissues compared with normal tissues, and it can inhibit the progression of osteosarcoma cells via targeting NFIA. Consistently, Gong et al. reported that lowly expressed miR-29a inhibited the invasion and migration of osteosarcoma cells via targeting DNMT3B [31]. Liu et al. reported that miR-29a could inhibit adhesion, migration, and invasion of osteosarcoma cells by suppressing CDC42 [32].

NFIA is a member of the nuclear factor I (NFI) family and plays an essential role in tumors. Overexpression of NFIA has been reported in esophageal squamous carcinoma and Glioblastomas and plays a tumor-promoting role [33, 34]. In this study, NFIA is predicted as a target gene of miR-29a via several databases and then it is validated by further researches.

In conclusion, our results revealed that macrophagesderived exosomes played an important role in osteosarcoma development and macrophages-derived exosomal lncRNA LIFR-AS1 promoted osteosarcoma cell proliferation and invasion via miR-29a/NFIA axis (Fig. 9). This study provided a new insight into the interaction between osteosarcoma cells and macrophages in the tumor microenvironment, and highlight the potential of LIFR-AS1/miR-29a/NFIA as novel therapeutic targets for osteosarcoma therapy. 


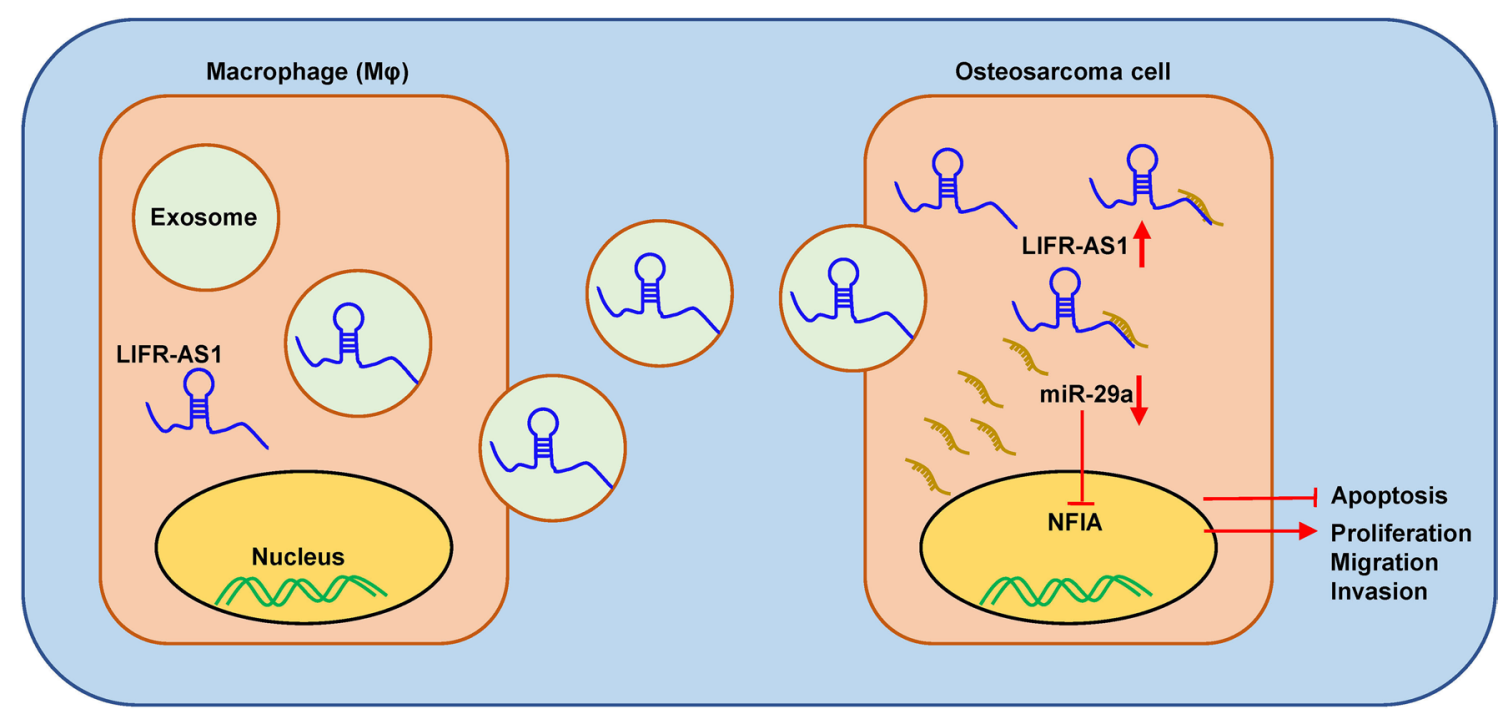

Fig. 9 A schematic drawing of macrophages-derived exosomal LIFR-AS1 enter osteosarcoma cells. LncRNA LIFR-AS1 is loaded in macrophages-derived exosomes and then delivered to osteosarcoma cells. In osteosarcoma cells, increased LncRNA LIFR-AS1 promoted proliferation, migration, and invasion of tumor cells and inhibit their apoptosis via miR-29a/NFIA/Smad3 axis

\section{Abbreviations}

TAMs: Tumor-associated macrophages; qRT-PCR: Quantitative real-time polymerase chain reaction; LIFR-AS1: LIFR antisense RNA 1; OS: Osteosarcoma; IncRNA: Long non-coding RNA; NFIA: Nuclear factor I A; FCM: Flow cytometry; Cck-8: Cell counting kit-8; EdU: 5-Ethynyl-2'-deoxyuridine; PBS: Phosphate buffer saline.

\section{Supplementary Information}

The online version contains supplementary material available at https://doi. org/10.1186/s12935-021-01893-0.

Additional file 1: Figure S1. Peripheral blood mononuclear cells (PBMCs) derived macrophage promote the proliferation and invasion of osteosarcoma cells. (A) The cck-8 assay for cell proliferation. (B) Colony formation assay. (C-D) Wound-healing assay. ${ }^{* *} p<0.01$. Figure S2. PBMCs induced Macrophages-derived exosomes promote osteosarcoma growth in vivo. (A) The effect of $M \varphi(P B M C)$-Exos on the growth of tumors was detected on xenograft. (B) The growth curve of xenograft. ${ }^{* *} \mathrm{p}<0.01$. Figure $\mathbf{S 3}$. The expression of miR-29a in both macrophage cells and exosomes after IncRNA LIFR-AS knockdown in macrophages. The result showed that LIFRAS knockdown can significantly upregulated the expression of miR-29a in macrophages cells but not in exosomes. ${ }^{* *} \mathrm{p}<0.01$, ns=no significant.

\section{Acknowledgements}

Not applicable.

\section{Authors' contributions}

$\mathrm{HZ}$ and WG designed the research, analyzed the data, and wrote the manuscript; $\mathrm{HZ}, Y Y, J W, Y H$ and TR performed the experiments; $H Y, C C L, H Q S$ and WW collected the tissue samples; JN and JL interpreted the data. All authors read and approved the final manuscript.

\section{Funding}

This work was supported by the National Natural Science Foundation of China (No. 82072970 and No. 81972509).

\section{Availability of data and materials}

The datasets used and/or analyzed during the current study are available from the corresponding author on reasonable request.

\section{Declarations}

Ethics approval and consent to participate

Informed consent was obtained from all patients and the research was approved by the Ethics Committee of Peking University People's Hospital. All animal experiments were performed with written confirmation authorized by the Animal Care and Use Committee of Peking University People's Hospital. Animal experiments complied with the ARRIVE guidelines and followed the National Institutes of Health Guide for the Care and Use of Laboratory Animals.

\section{Consent for publication}

Not applicable.

\section{Competing interests}

The authors declare that they have no competing interests.

\section{Author details}

${ }^{1}$ Musculoskeletal Tumor Center, Peking University People's Hospital, No. 11 Xizhimen South Street, Beijing 100044, People's Republic of China. ${ }^{2}$ Beijing Key Laboratory of Musculoskeletal Tumor, Beijing, People's Republic of China.

Received: 5 January 2021 Accepted: 23 March 2021

Published online: 01 April 2021

\section{References}

1. Luetke A, Meyers PA, Lewis I, Juergens H. Osteosarcoma treatmentwhere do we stand? A state of the art review. Cancer Treat Rev. 2014;40(4):523-32.

2. He F, Zhang W, Shen Y, Yu P, Bao Q, Wen J, Hu C, Qiu S. Effects of resection margins on local recurrence of osteosarcoma in extremity and pelvis: systematic review and meta-analysis. Int J Surg. 2016;36(Pt A):283-92.

3. Shi ZW, Wang JL, Zhao N, Guan Y, He W. Single nucleotide polymorphism of hsa-miR-124a affects risk and prognosis of osteosarcoma. Cancer Biomark. 2016;17(2):249-57.

4. Provisor AJ, Ettinger LJ, Nachman JB, Krailo MD, Makley JT, Yunis EJ, Huvos AG, Betcher DL, Baum ES, Kisker CT, et al. Treatment of nonmetastatic osteosarcoma of the extremity with preoperative and postoperative chemotherapy: a report from the Children's Cancer Group. J Clin Oncol. 1997;15(1):76-84 
5. Ottaviani G, Jaffe N. The epidemiology of osteosarcoma. Cancer Treat Res. 2009;152:3-13.

6. Vassiliou LV, Lalabekyan B, Jay A, Liew C, Whelan J, Newman L, Kalavrezos N. Head and neck sarcomas: a single institute series. Oral Oncol. 2017:65:16-22.

7. Wang M, Zhao J, Zhang L, Wei F, Lian Y, Wu Y, Gong Z, Zhang S, Zhou J, Cao $\mathrm{K}$, et al. Role of tumor microenvironment in tumorigenesis. J Cancer. 2017;8(5):761-73.

8. Zhu J, Zhi Q, Zhou BP, Tao M, Liu J, Li W. The role of tumor associated macrophages in the tumor microenvironment: mechanism and functions. Anticancer Agents Med Chem. 2016;16(9):1133-41.

9. Liang X, Guo W, Ren T, Huang Y, Sun K, Zhang H, Yu Y, Wang W, Niu J. Macrophages reduce the sensitivity of osteosarcoma to neoadjuvant chemotherapy drugs by secreting Interleukin-1 beta. Cancer Lett. 2020;480:4-14.

10. Martinez FO, Gordon S. The M1 and M2 paradigm of macrophage activation: time for reassessment. F1000Prime Rep. 2014;6:13.

11. Han Y, Guo W, Ren T, Huang Y, Wang S, Liu K, Zheng B, Yang K, Zhang H, Liang $X$. Tumor-associated macrophages promote lung metastasis and induce epithelial-mesenchymal transition in osteosarcoma by activating the COX-2/STAT3 axis. Cancer Lett. 2019:440-441:116-25.

12. Gezer U, Ozgur E, Cetinkaya M, Isin M, Dalay N. Long non-coding RNAs with low expression levels in cells are enriched in secreted exosomes. Cell Biol Int. 2014;38(9):1076-9.

13. Cheng J, Meng J, Zhu L, Peng Y. Exosomal noncoding RNAs in Glioma: biological functions and potential clinical applications. Mol Cancer. 2020;19(1):66.

14. Huang Z, Zhou JK, Peng Y, He W, Huang C. The role of long noncoding RNAs in hepatocellular carcinoma. Mol Cancer. 2020;19(1):77.

15. Peng WX, Koirala P, Mo YY. LncRNA-mediated regulation of cell signaling in cancer. Oncogene. 2017;36(41):5661-7.

16. Bhan A, Soleimani M, Mandal SS. Long noncoding RNA and cancer: a new paradigm. Cancer Res. 2017;77(15):3965-81.

17. Xu F, Li H, Hu C. LIFR-AS1 modulates Sufu to inhibit cell proliferation and migration by miR-197-3p in breast cancer. 2019. Biosci Rep. https://doi. org/10.1042/BSR20180551.

18. Zhang $H$, Yang $K$, Ren $T$, Huang $Y$, Tang $X$, Guo W. miR-16-5p inhibits chordoma cell proliferation, invasion and metastasis by targeting Smad3. Cell Death Dis. 2018;9(6):680.

19. Xin S, Wei G. Prognostic factors in osteosarcoma: a study level metaanalysis and systematic review of current practice. J Bone Oncol. 2020;21:100281

20. Yousefzadeh Y, Hallaj S, Baghi Moornani M, Asghary A, Azizi G, Hojjat-Farsangi M, Ghalamfarsa G, Jadidi-Niaragh F. Tumor associated macrophages in the molecular pathogenesis of ovarian cancer. Int Immunopharmacol. 2020;84:106471

21. Kelleher FC, O'Sullivan H. Monocytes, macrophages, and osteoclasts in osteosarcoma. J Adolesc Young Adult Oncol. 2017;6(3):396-405.

22. Buddingh EP, Kuijjer ML, Duim RA, Burger H, Agelopoulos K, Myklebost $\mathrm{O}$, Serra M, Mertens F, Hogendoorn PC, Lankester AC, et al. Tumor-infiltrating macrophages are associated with metastasis suppression in high-grade osteosarcoma: a rationale for treatment with macrophage activating agents. Clin Cancer Res. 2011;17(8):2110-9.
23. Zhou Q, Xian M, Xiang S, Xiang D, Shao X, Wang J, Cao J, Yang X, Yang B, Ying $\mathrm{M}$, et al. All-trans retinoic acid prevents osteosarcoma metastasis by inhibiting M2 polarization of tumor-associated macrophages. Cancer Immunol Res. 2017;5(7):547-59.

24. Su Y, Zhou Y, Sun YJ, Wang YL, Yin JY, Huang YJ, Zhang JJ, He AN, Han K, Zhang $\mathrm{HZ}$, et al. Macrophage-derived CCL18 promotes osteosarcoma proliferation and migration by upregulating the expression of UCA1. Mol Med (Berl). 2019;97(1):49-61.

25. LeBleu VS, Kalluri R. Exosomes as a multicomponent biomarker platform in cancer. Trends Cancer. 2020;6:9.

26. Zhang H, Wang J, Ren T, Huang Y, Liang X, Yu Y, Wang W, Niu J, Guo W. Bone marrow mesenchymal stem cell-derived exosomal miR-206 inhibits osteosarcoma progression by targeting TRA2B. Cancer Lett. 2020.

27. Wang L, Li J, Zhao H, Hu J, Ping Y, Li F, Lan Y, Xu C, Xiao Y, Li X. Identifying the crosstalk of dysfunctional pathways mediated by IncRNAs in breast cancer subtypes. Mol Biosyst. 2016;12(3):711-20.

28. Zhu H, Lu J, Zhao H, Chen Z, Cui Q, Lin Z, Wang X, Wang J, Dong H, Wang $\mathrm{S}$, et al. Functional long noncoding RNAs (IncRNAs) in clear cell kidney carcinoma revealed by reconstruction and comprehensive analysis of the IncRNA-miRNA-mRNA regulatory network. Med Sci Monit. 2018;24:8250-63.

29. Liu K, Yao H, Wen Y, Zhao H, Zhou N, Lei S, Xiong L. Functional role of a long non-coding RNA LIFR-AS1/miR-29a/TNFAIP3 axis in colorectal cancer resistance to pohotodynamic therapy. Biochim Biophys Acta Mol Basis Dis. 2018;1864(9 Pt B):2871-80.

30. Wang JY, Zhang Q, Wang DD, Yan W, Sha HH, Zhao JH, Yang SJ, Zhang HD, Hou JC, Xu HZ, et al. MiR-29a: a potential therapeutic target and promising biomarker in tumors. 2018. Biosci Rep. https://doi.org/10.1042/BSR20 171265.

31. Gong HL, Tao Y, Mao XZ, Song DY, You D, Ni JD. MicroRNA-29a suppresses the invasion and migration of osteosarcoma cells by regulating the SOCS1/NF-kappaB signalling pathway through negatively targeting DNMT3B. Int J Mol Med. 2019:44(4):1219-32.

32. Liu ZJ, Chen SG, Yang YZ, Lu SJ, Zhao XM, Hu B, Zhang L. miR-29a inhibits adhesion, migration, and invasion of osteosarcoma cells by suppressing CDC42. Int J Clin Exp Pathol. 2019;12(11):4171-80.

33. Yang B, Zhou ZH, Chen L, Cui X, Hou JY, Fan KJ, Han SH, Li P, Yi SQ, Liu Y. Prognostic significance of NFIA and NFIB in esophageal squamous carcinoma and esophagogastric junction adenocarcinoma. Cancer Med. 2018;7(5):1756-65.

34. Lee JS, Xiao J, Patel P, Schade J, Wang J, Deneen B, Erdreich-Epstein A, Song HR. A novel tumor-promoting role for nuclear factor IA in glioblastomas is mediated through negative regulation of p53, p21, and PAl1. Neuro Oncol. 2014;16(2):191-203.

\section{Publisher's Note}

Springer Nature remains neutral with regard to jurisdictional claims in published maps and institutional affiliations.

Ready to submit your research? Choose BMC and benefit from:

- fast, convenient online submission

- thorough peer review by experienced researchers in your field

- rapid publication on acceptance

- support for research data, including large and complex data types

- gold Open Access which fosters wider collaboration and increased citations

- maximum visibility for your research: over 100M website views per year

At BMC, research is always in progress.

Learn more biomedcentral.com/submissions 